\title{
The largest epidermal cyst with vitiligo lesions following female genital mutilation: a case report and literature review
}

\author{
Melike Kibar Ozturk ${ }^{\circledR}$, İlkin Zindanci ${ }^{1}$, Ebru Zemheri² ${ }^{2}$ Cumhur Çakır³
}

\begin{abstract}
Epidermoid vulvar cystic lesions are proliferations of epidermal cells that can occur as a complication of female genital mutilation (FGM), which is still a common practice in many cultures, especially in Africa. A 36-year-old Sudanese woman presented with an enlarged clitoral mass that had first appeared 2 years earlier. Her medical history showed that she had undergone FGM when she was 3 years old. A perineal examination revealed a mobile, nontender, rounded cystic swelling with vitiligo lesions. After the cyst was excised, it revealed a $13 \times 11 \times 11 \mathrm{~cm}$ unilocular round mass. An epidermoid cyst was reported following microscopy. Follow-up 6 months later revealed a good result with no recurrence. To date, this is the largest epidermoid cyst following FGM and the first one with vitiligo lesions reported in the literature.
\end{abstract}

Keywords: epidermal cyst, vitiligo, female genital mutilation

Received: 12 February 2018 | Returned for modification: 18 April 2018 | Accepted: 26 June 2018

\section{Introduction}

Cystic lesions such as epidermal vulvar cysts are extremely rare without a prior surgical operation following trivial trauma, infibulation, circumcision, or genital piercing $(1,2)$. The majority of cases occur as a complication of female genital mutilation (FGM), which is still a common procedure in many cultures-especially in Africa-on neonates (1-14).

FGM has been practiced for centuries in more than 30 countries and is most prevalent in African countries such as Nigeria, Ethiopia, Sudan, and Egypt, and in some areas of the Middle East (14). FGM is classified by the World Health Organization (WHO), and type III (removal of the clitoris and labia minora and narrowing of the vaginal orifice) is the most common procedure performed in some countries (15-17). Various complications are observed after circumcisions, such as epidermal cysts (18).

This case report is of a 36-year-old woman with a history of type III FGM and a giant clitoral epidermal cyst accompanied by vitiligo lesions. To date, this is the largest epidermoid cyst following FGM and the first one with vitiligo lesions reported in the literature.

\section{Case report}

A 36-year-old Sudanese woman presented with an enlarged and painful clitoral mass with vitiligo lesions that was causing sexual difficulties and psychological distress. Her husband suspected that she had been bewitched into having a single scrotum (Fig. 1). The enlargement had been present for 2 years and had grown rapidly within the previous 6 months. The mass had started growing larger and causing a dragging sensation in the vulva and significant discomfort, especially during intercourse, but the patient had not experienced any inflammation or infection of the mass. She did not have a history of cystic lesions following trauma or surgery at any other sites. The patient had had vitiligo lesions in the same location as the cyst for 1 year. Over the course of the preceding year, the vitiligo lesions had increased in diameter in the same proportion as the cystic mass. The initial vitiligo lesion was on her umbilical scar following gastrointestinal surgery 3 years earlier. She did not have any additional vitiligo lesions except on the mutilation scar. The patient had no history of autoimmune disease. Her family history was negative for vitiligo.

The patient had had regular cyclic menses since she was 13 years old. She had no history of birth, miscarriages, or genital piercing. She did not have a history of urogenital infections. Her medical history included type III FGM at the age of three, performed by a village midwife. A perineal examination revealed a 13 $\times 13 \mathrm{~cm}$ mobile, nontender, rounded cystic swelling in the clitoral area, which was covered with normal skin other than the depigmentated skin touching the medial thighs and vestibulum (Fig. 1). The cyst was neither fixed to the symphysis pubis nor involved

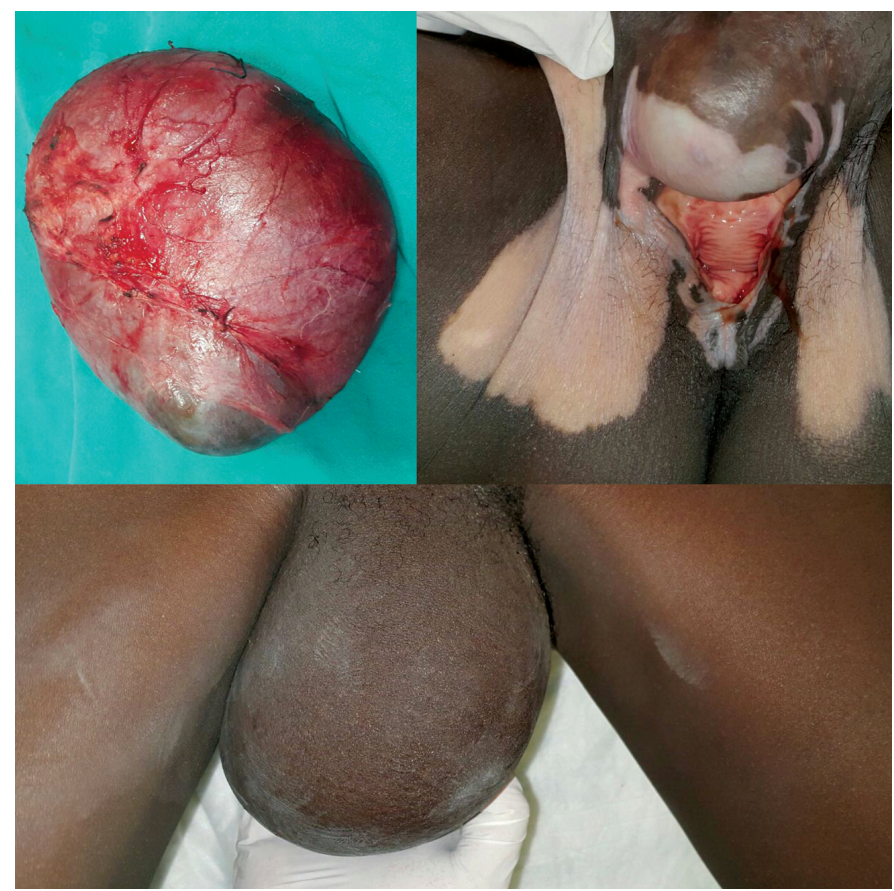

Figure $1 \mid$ Clinical and postoperative picture of the giant epidermoid cyst with vitiligo lesions. 


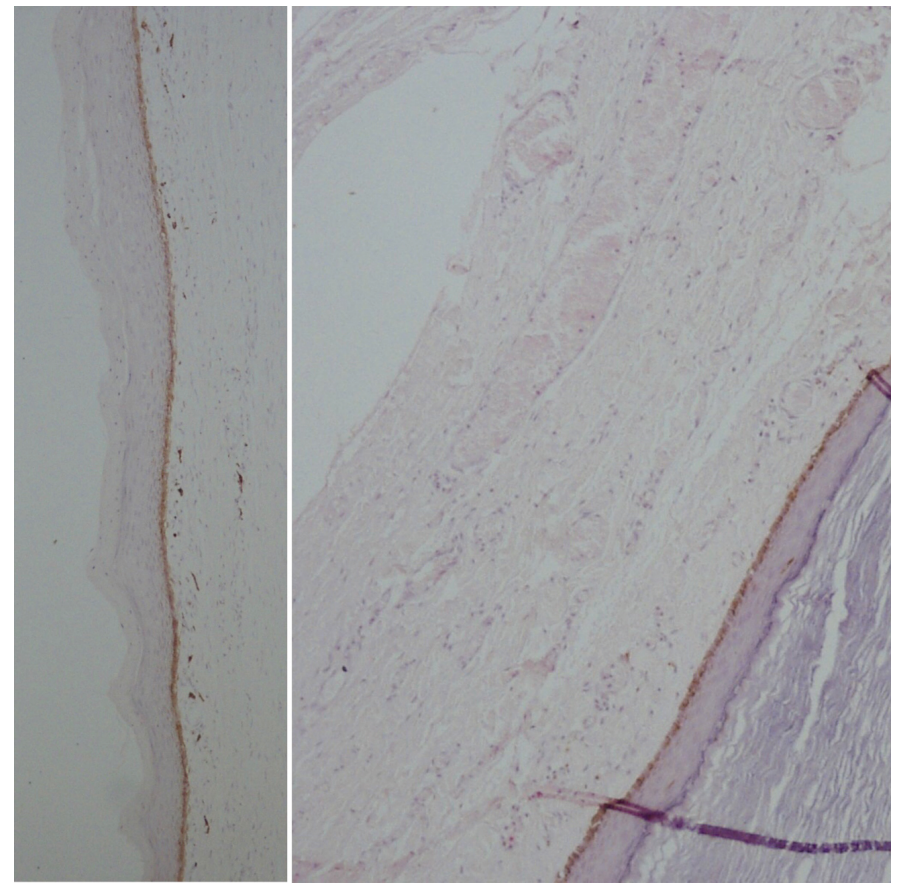

Figure 2 | Histopathological appearance of the epidermoid cyst lined by an epidermis-like epithelium including a granular cell layer and filled with laminated keratin.

\section{Discussion}

Various types of cysts can occur in the clitoral region, including atheroma, dermoid cysts, dysontogenetic cysts, and epidermoid cysts (14). Such cysts can cause clitoromegaly and can be described as ambiguous genitalia when present at birth (19). Many of these cysts resolve spontaneously (20), but in this case there was a late onset of ambiguous genitalia that grew within months.

Following FGM, epidermoid cysts are mainly seen in the clitoris, labia majora, and labia minora, at various rates according to the type of circumcision $(1,8,21,22)$. According to the WHO, two million new FGMs are performed annually in the world $(16,23)$. Circumcisions are usually performed on neonates under traditional conditions, often by older women that are midwives (24, 25). The patient described in this report had a female circumcision when she was 3 years old.

FGM is classified by the WHO into four types $(16,26,27)$. These are Type I: removal of the prepuce with or without removal of all or part of the clitoris; Type II: removal of the prepuce, clitoris, and part of the labia; and Type III: removal of all or part of the external genitalia along with stitching or narrowing of the vaginal opening (27). This kind of mutilation, Type III, also called infibulation (5), is the most extreme type. Incisions are made in the labia majora to create raw surfaces that are then either stitched together or kept in close contact until they seal and form a cover for the urethral meatus. A very small orifice is left for the passage. In many regions, this is the most common procedure performed; for example, 98\% of FGMs are Type III in Djibouti and Somalia (1517). Various complications are seen after circumcision, such as bleeding, infection, shock, menstrual problems, difficulties with urination, common urinary tract infections, urinary retention, tetanus (which can lead to mortality), inguinal pain, difficulties with sexual intercourse, a genital circumcision scar-especially at the vulvar region-and a cystic or solid mass of variable size, as found in this patient (18).

Epidermoid cysts following FGM are not rare. A review of the literature is summarized in Table 1. According to the literature, the time from circumcision to the development of the cyst is variable, but a delay of more than 30 years - as in the present case-is very infrequent $(10,12,13)$. In 2010 Asante et al. reported a 37-yearold female from Guinea with a large clitoral epidermal inclusion cyst of the clitoris 30 years after FGM with a history of 6 months (10). In 2015 Birge et al. reported a female from Nyala, Sudan with a vulvar epidermoid cyst after FGM. They reported an interval of 35 years between FGM and the surgical intervention (12). Finally, in 2016 Victoria Martinez et al. reported a 37-year-old female patient from Nigeria that developed a cyst more than 30 years after FGM (13). Similar to these previous reports, the patient in the case reported here had a cyst 31 years after FGM.

The largest epidermoid mass that developed in the labium major was reported by Yang et al. and was about $12 \mathrm{~cm}$ in size with 10 years of clinical history (28). From this perspective, a mass of $13 \mathrm{~cm}$ accompanied by vitiligo lesions with a delay of 31 years in presentation is the largest epidermoid mass with peculiar characteristics reported in the literature.

The case presented in this paper is different from previous reports in that it involves vitiligo lesions. Vitiligo is an acquired, chronic, depigmenting disorder of the skin with an estimated prevalence of $0.5 \%$ of the general population. It is characterized by the development of white macules on affected areas. Multiple mechanisms are involved in vitiligo; namely, genetic predisposition, environmental triggers, metabolic abnormalities, impaired renewal, and altered inflammatory and immune responses (29). In this patient, vitiligo lesions likely occurred due to the Koebner phenomenon. The Koebner phenomenon refers to the development of isomorphic lesions in the traumatized, uninvolved skin of patients that have skin diseases, including psoriasis, vitiligo, and lichen planus. These injuries can be non-penetrating blunt trauma-such as stretching, friction, compression, and vibration-similar to this patient's genital trauma (30). In addition, the patient had a history of an old and healed vitiligo lesion on her umbilical scar from gastrointestinal surgery; this further supports the development of vitiligo lesions as a consequence of the Koebner phenomenon.

Table 1 | Review of reports of patients with epidermoid vulvar cysts after female genital mutilation.

\begin{tabular}{lllc}
\hline Year & Author (Reference no.) & Country of origin & Patients $(n)$ \\
\hline 1992 & Dirie and Lindmark (5) & Somalia & 290 \\
1995 & Hanly and Ojeda (6) & Saudi Arabia & 10 \\
1999 & Baaij et al. (7) & Somalia & 1 \\
1999 & Abudaia et al. (19) & Saudi Arabia & 1 \\
1999 & Adekunle et al. (8) & Nigeria & 39 \\
2001 & Rouzi et al. (4) & Saudi Arabia & 21 \\
2004 & Yoong et al. (9) & Somalia & 1 \\
2010 & Asante et al. (10) & Guinea & 1 \\
2010 & Rouzi (11) & Saudi Arabia & 15 \\
2010 & Osifo (2) & Nigeria & 37 \\
2015 & Birge et al. (12) & Sudan & 1 \\
2016 & Victoria-Martinez et al. (13) & Nigeria & 1 \\
2018 & Kibar Ozturk, present case & Sudan & 1 \\
\hline
\end{tabular}

\section{Conclusion}

This report describes a 36-year-old woman with a sizeable $(13 \times 11$ $\times 11 \mathrm{~cm})$ clitoral epidermal cyst accompanied by vitiligo lesions secondary to FGM. FGM is still common in Africa and among immigrants from Africa, especially in culturally and traditionally closed societies. More investigations are warranted to elaborate on the short- and long-term complications of FGM. 


\section{References}

1. Schmidt A, Lang U, Kiess W. Epidermal cyst of the clitoris: rare cause of clitoromegaly. Eur J Obstet Gynecol Reprod Biol. 1999;87:163-5.

2. Osifo OD. Post genital mutilation giant clitoral epidermoid inclusion cyst in Benin City, Nigeria. J Pediatr Adolesc Gynecol. 2010;23:336-40.

3. Rizk DE, Mohammed KH, Joshi SU, Al-Shabani AY, Bossmar TR. A large clitoral epidermoid inclusion cyst first presenting in adulthood following childhood circumcision. J Obstet Gynaecol. 2007;27:445-8.

4. Rouzi AA, Sindi O, Radhan B, Ba'aqeel H. Epidermal clitoral inclusion cyst after type I female genital mutilation. Am J Obstet Gynecol. 2001;185:569-71.

5. Dirie MA, Lindmark $G$. The risk of medical complications after female circumcision. East Afr Med J. 1992;69:479-82.

6. Hanly MG, Ojeda VJ. Epidermal inclusion cysts of the clitoris as a complication of female circumcision and pharaonic infibulation. Cent Afr J Med. 1995;41:22-4.

7. Baaij M, Kagie MJ. Female circumcision: histories of 3 patients. Ned Tijdschr Geneeskd. 1999;143:1721-4.

8. Adekunle AO, Fakokunde FA, Odukogbe AA, Fawole AO. Female genital mutilation - postcircumcision vulval complications in Nigerians. J Obstet Gynaecol. 1999;19:632-5.

9. Yoong WC, Shakya R, Sanders BT, Lind J. Clitoral inclusion cyst: a complication of type I female genital mutilation. J Obstet Gynaecol. 2004;24:98-9.

10. Asante A, Omurtag K, Roberts C. Epidermal inclusion cyst of the clitoris 30 years after female genital mutilation. Fertil Steril. 2010;94:1097.e1-3.

11. Rouzi AA. Epidermal clitoral inclusion cysts: not a rare complication of female genital mutilation. Hum Reprod. 2010;25:1672-4.

12. Birge O, Ozbey EG, Arslan D, Erkan MM, Demir F, Akgor U. Vulvar epidermoid cyst and type 2 radical genital mutilation. Case Rep Obstet Gynecol. 2015;2015: 520190.

13. Victoria-Martinez AM, Cubells-Sanchez L, Martinez-Leborans L, Sanchez-Carazo JL, de Miquel VA. Vulvar epidermal inclusion cyst as a long-term complication of female genital mutilation. Indian J Dermatol. 2016;61:119.

14. Anderson-Mueller BE, Laudenschlager MD, Hansen KA. Epidermoid cyst of the clitoris: an unusual cause of clitoromegaly in a patient without history of female circumcision. J Pediatr Adolescent Gynecol. 2009;22:e130-2.

15. Joint WHO/FIGO Task Force. Female circumcision: female genital mutilation. Eur J Obstet Gynecol Reprod Biol. 1992;45:153-4.

16. Kiragu K. Female genital mutilation: a reproductive health concern. Popul Rep J. 1995:1-4.
17. Ulku CH, Uyar Y, Kocaogullar Y, Avunduk MC. latrogenic epidermal inclusion cyst of the parapharyngeal space: unusual complication of ear surgery. Skull Base. 2004;14:47-51.

18. World Health Organization. Eliminating female genital mutilation: an interagency statement - OHCHR, UNAIDS, UNDP, UNECA, UNESCO, UNFPA, UNHCR, UNICEF, UNIFEM, WHO [Internet]. Geneva, Switzerland: WHO Press; 2008 [cited 2018 Jan 28]. Available from: http://www.who.int/reproductivehealth/publications/fgm/9789241596442/en/.

19. Abudaia J, Habib Z, Ahmed S. Dermoid cyst: a rare cause of clitorimegaly. Pediatr Surg Int 1999;15:521-2.

20. Merlob P, Bahari C, Liban E, Reisner SH. Cysts of the female external genitalia in the newborn infant. Am J Obstet Gynecol 1978;132:607-10.

21. World Health Organization. Female genital mutilation Fact Sheet 241 [Internet]. World Health Organization; 2014 [cited 2018 Jan 28]. Available from: http:// www.who.int/mediacentre/factsheets/fs241/en/.

22. Linck D, Hayes MF. Clitoral cyst as a cause of ambiguous genitalia. Obstet Gynecol. 2002;99:963-6.

23. Macready N. Female genital mutilation outlawed in United States. BMJ. 1996; 313:1103.

24. Reisel D, Creighton SM. Long term health consequences of female genital mutilation. Maturitas. 2015;80:48-51.

25. Horowitz CR, Jackson JC. Female "circumcision": African women confront American medicine. J Gen Intern Med. 1997;12:491-9.

26. Black JA, Debelle GD. Female genital mutilation in Britain. BMJ. 1995;310:1590-2.

27. World Health Organization Division of Family Health. Female genital mutilation: report of a WHO technical working group, Geneva 17-19 July 1995. Geneva: World Health Organization; 1996.

28. Yang WC, Huang WC, Yang JM, Lee FK. Successful management of a giant primary epidermoid cyst arising in the labia majora. Taiwan J Obstet Gynecol. 2012;51: 112-4.

29. Boniface K, Seneschal J, Picardo M, Taïeb A. Vitiligo: focus on clinical aspects, immunopathogenesis, and therapy. Clin Rev Allergy Immunol. 2018;54:52-67.

30. Thappa DM. The isomorphic phenomenon of Koebner. Indian J Dermatol Venereol Leprol. 2004;70:187-9. 